


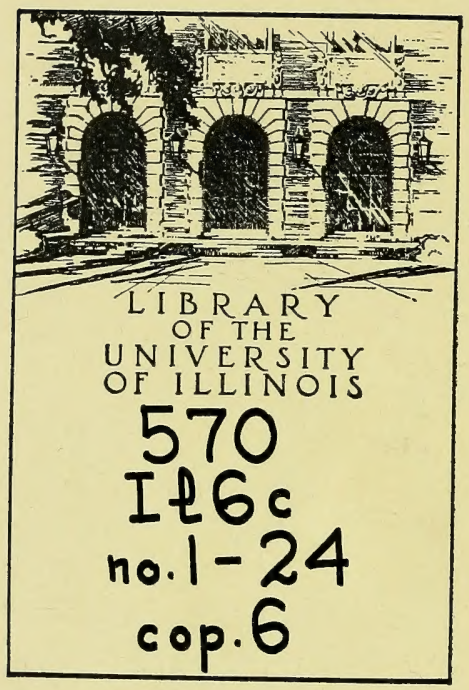

NATURAL HISTORY
SURVEY 
Digitized by the Internet Archive in 2011 with funding from

University of Illinois Urbana-Champaign 





\section{The Danger from House-flies and How to Control It}

The house-fly pest is dangerous to health, and the cause of many deaths, especially of children, in summer time. To diminish this danger, keep the premises clean and kill the flies; and to avoid it entirely, induce neighbors and town authorities to do the same. Clean UP, KEEP CLFAN, AND KIJL THE FLY, is the admonition of science to the householder, the community, and the city or town.

House-flies lay their eggs in a great variety of decaying or fermenting substances-most frequently in the fresh manure of horses and cattle in stables and barns, but often in kitchen garbage also, and in other and more offensive household wastes. They hatch from the egg as footless, headless maggots which feed upon the substances in which they were born. In the course of a few days the maggot changes to a brown, oval, motionless object called the pupa, and out of this comes the winged house-fly, soon ready to produce eggs for another generation. In hot weather the eggs may hatch, the maggot grow up and pupate, and the winged fly come forth, all in from nine to fourteen days. In cool weather, these changes go on more slowly.

The winged fly lives mainly on fluid or semifluid foods, some of which are of kinds most dangerous to human health. Thus flies may sip up the sputum of a person ill with consumption, in which are the germs by which that disease is spread from one person to another; they may feed on the wastes of a sick room, and on other filth, and so become fouled with fluids containing the germs of typhoid fever, of summer complaint, and of dysentery; and then they may visit our houses, restaurants, and groceries, crawling over the food which we are about to eat, leaving a trall of disease germs as they go, and they may infect the milk and other fluids which we are about to drink. In this way they often spread abroad the most serious diseases and cause the death each year of hundreds and thousands of people, especially of children, in summer time in cities and towns.

Although in the maggot stage the house-fly may be of considerable service as a scavenger, it does at best very imperfectly what we ought not 

to leave to the chance operations of insects, but should do systematically and thoroughly on our own account. The winged fly, on the other hand, is always a nuisance, and often a highly dangerous pest; and its destruction is both a personal and a social duty. One who parmits flies to enter his house or to get access to his food, is guilty of negligence likely to injure his own health and that of his family; one who permits flies to breed on his premises is to that extent himself a dangerous member of society; and the community which does nothing to control the house-fly pest is to that extent delinquent in the discharge of its duties towards its own people. Every person may, it is true, protect himself in great measure, even if living in a negligent community, but only with considerable trouble and at unnecessary expense. Community work is necessary to complete success.

In order that house-flies may live and multiply, the adults must find food for themselves and suitable places and substances in which to lay their eggs; such substances must continue in a condition to serve as food for the maggots until these have got their growth and have changed to the pupa; this infested material must not be destroyed until the flies have escaped from the pupa and taken wing; and then, of course, the winged flies must live until they have laid a new lot of eggs. If any one of these conditions can be suppressed, the house-fly itself will be suppressed also.

As this insect breeds only in substances which ought not to be allowed to lie exposed, the plague of flies is a part of our punishment for unclean surroundings; and to clean up and keep clean, is thus the first requirement. In cities and towns the manure from a stable for a single horse should bo closely packed, every day, into one or more tight barrels or boxes with close-fitting covers, and the contents of these receptacles should be hauled away once a week, or even twice a week in warmest weather. In the country, where the stables are larger, each should have an inclosure or pit Into which the manure may be pitched daily, and from which it may be hauled away. This inclosure must be made fly-proof by close-fitting doors, but should have a screened opening for ventilation. Stables should have floors which are water-tight, thus preventing the accumulation of moist, fermenting material in which flies are IIkely to breed. Pits or bins in which the manure is temporarily stored should be cleaned out thoroughly when emptied, and if any fly pupæ remain they should be killed by sprinkling lightly with kerosene. No garbage, offal, or decaying and fermenting refuse of any description should be allowed to remain on the premises. Even ashes become dangerous if mixed with moist garbage. Box privies, If they can not be abolished, should at least be made fly-tight, and their contents should be covered regularly with copperas, which will keep down odors, and prevent the development of house-fly maggots. Garbage cans should be kept tightly covered, and thoroughly cleaned out when emptied, and sprinkled inside with kerosene to make sure that no larvæ or pupæ are left alive. Where flies are being bred in neighboring places beyond 

one's control, they must be kept out of the house, so far as possible, by screened doors and windows, and caught and killed if they make their way into the rooms. Sticky fly-paper, helped out by the favorite operation of "swatting the fly", will ordinarily serve this purpose. An efficient fly poison may be made by diluting formalin with five or six times as much water, and adding sugar enough to make it sweet. This should be set about in shallow dishes, and other liquids kept beyond the reach of the flies. Wire fly-traps, baited with attractive fly food, may be used to advantage in the open air; for the number of flies which will seek admission to the house may thus be diminished, as well as the number of fly maggots and of flies of later generations to be bred in the neighborhood.

The principal contents of this little circular may be summarized largely in the words of a poster issued by the Florida State Board of Health:

Flles breed in horse manure, cow dung, decaying vegetables, garbage of all description, dead animals, and human excrement.

Flies are Nature's scavengers, it is true, but they become an intolerable nuisance and DANGER when entering human dwellings and contaminating foods.

The presence of flies is a direct evidence of careless housekeeping and the existence of filth in some form on or near the premises.

Remember that when and where absolute cleanliness prevalls there will be no flles.

Look dally after the garbage cans. See that they are carefully sprinkled with hydrated lime or kerosene and effectively covered.

Remove all manure from stables every three or four days, and when removed cover with hydrated high calcium lime.

Look carefully after the cuspidors. They require constant attention. This is particularly true in hotels, boarding houses, station houses, rallroad stations, and, in fact, wherever people congregate in large numbers.

Flies are fond of feasting on tuberculosis sputum, and hover around cuspidors. The specks of files contain live tubercle bacilli after they have eaten tuberculosis sputum, showing that the bacilli will pass through the digestive tract of the fiy in an active infective state.

Flies carry on their mouth parts, and on their legs, germs of decay and disease, on which they have recently fed, and then crawl over food, infecting it, unless shut out by screens.

Keep flles from the SICK, especially those iil with communicable or contagious diseases. If the room is not screened the patient should be treated under a net, both for safety to others as well as for individual comfort.

SCREEN ALL FOOD. Apply this rule, not only to food prepared at 

home, but to food-stuffs offered for sale, and especially fruits, salads, and all other things which do not require to be cooked; for-

Flies crawl over fruit when exposed for sale, unguarded by screens, and many people do not wash fruit before eating it. This is a common source of human infection, particularly if a case of typhoid fever near by is being carelessly handled.

Don't forget that flles will carry the bacilli of typhoid fever from the stools of the patient (if left exposed and not disinfected), if given an opportunity, to the food in the kitclien and dining-room.

The great secret of freedom from flies is CLEANLINESS, FIRST, and a screening of all openings of the home, especially of the kitchen and the dining-room.

Urbana, Illinois,

Stephen A. Forbes,

State Entomologist.

June 1, 1911. 




UNIVERSITY OF ILLINOIS-URBANA

5701L6C

CIRCULAR

C006

1-24

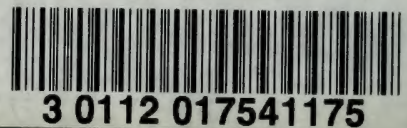

